\title{
Effect of Initial Intensive Insulin Therapy Followed by Sitagliptin on $\beta$ Cell Function in Patients with New Onset Type 2 Diabetes
}

Hua $X u^{1 \#}$, Huan Zhou ${ }^{1 \#}$, Xiangyu Teng ${ }^{1}$, Tzuchun Lin ${ }^{1}$, Rilu Feng ${ }^{1}$, Qianjing Liu ${ }^{1}$, Huiying Qiu ${ }^{1}$, Chris K Rayner ${ }^{2,3}$, Jing Ma ${ }^{1^{*}}$ and Wei Liu ${ }^{1 *}$

${ }^{1}$ Division of Endocrinology and Metabolism, Department of Internal Medicine, Renji Hospital affiliated to Shanghai Jiaotong University, Shanghai, China

${ }^{2}$ Discipline of Medicine, University of Adelaide, Adelaide, Australia

${ }^{3}$ Centre of Research Excellence in Translating Nutritional Science to Good Health, University of Adelaide, Adelaide, Australia

"Corresponding author: Dr. Jing Ma and Dr. Wei Liu, Division of Endocrinology and Metabolism, Department of Internal Medicine, Renji Hospital affiliated to Shanghai Jiaotong University, No.160 Pujian Road, Pudong New Area Shanghai, China, Tel: +86-21-68383073; Fax: +86-21-58394262; E-mail: majing3436@163.com; sue_liuwei@163.com

Received date: August 10, 2018; Accepted date: August 30, 2018; Published date: September 05, 2018

Copyright: $\odot 2018 \mathrm{Xu} \mathrm{H}$, et al. This is an open-access article distributed under the terms of the Creative Commons Attribution License, which permits unrestricted use, distribution, and reproduction in any medium, provided the original author and source are credited.

\#Contributed equally to this work.

\begin{abstract}
Objective: It is established that early insulin therapy can improve both $\beta$ cell function and glycaemic control in newly diagnosed type 2 diabetic patients. The dipeptidyl peptidase-4 (DPP-4) inhibitor, sitagliptin, can preserve or even increase the number of $\beta$ cells in animal models of diabetes. Therefore, we aimed to determine whether treatment with sitagliptin after initial intensive insulin therapy would further reduce glycaemia and preserve $\beta$ cell function in new-onset type 2 diabetes.
\end{abstract}

Methods: 48 Chinese patients with newly diagnosed type 2 diabetes (fasting blood glucose concentration 13.42 $\pm 0.38 \mathrm{mmol} / \mathrm{L} ; \mathrm{HbA} 1 \mathrm{c}: 11.8 \pm 0.2 \%$ ) were recruited. All received insulin pump therapy for two weeks, followed by sitagliptin (100mg orally once daily) for three months. Arginine tests were performed at baseline, after two-weeks' insulin pump therapy, and after 3 months' sitagliptin therapy. Blood samples were collected at baseline, before and after the treatment with sitagliptin for measurement of blood glucose, plasma insulin and lipids profiles. $\beta$ cell function was evaluated by HOMA- $\beta$ and the insulin response to arginine.

Results: Fasting blood glucose concentrations were substantially decreased after two weeks' insulin therapy $(P<0.01)$, and were further reduced after 3 months' treatment with sitagliptin $(P<0.01)$. HOMA- $\beta$ and HOMA-IR were improved $(P<0.01)$ after two weeks' treatment with insulin, while HOMA- $\beta$ was further improved after 3 months' sitagliptin $(P<0.01)$. However, the insulin response to arginine did not increase after two weeks' insulin therapy, but did improve after sitagliptin $(\mathrm{P}<0.05)$.

Conclusions: Intensive insulin therapy improved both glycaemic control and $\beta$ cell function in newly diagnosed Chinese type 2 diabetes, and the improvements in $\beta$ cell function was preserved after 3 months of sitagliptin.

Keywords: Type 2 diabetes; Initial intensive insulin therapy; Dipeptidyl peptidase- 4

\section{Introduction}

There is a worldwide epidemic of diabetes, with the prevalence in China estimated at almost $12 \%$ in 2013 [1]. Impaired $\beta$-cell function outweighs insulin resistance in the development of type 2 diabetes in Asian populations [2]. American Association of Clinical Endocrinologists (AACE) recommended that treatment for newly diagnosed type 2 patients should be determined by glycated hemoglobin (HbA1C) [3]. For example, patients with $\mathrm{HbA1C}>9.0 \%$ would benefit more from insulin therapy, which can rapidly eliminate gluco-toxicity and reduce the excessive stimulation of $\beta$ cells [4]. It has been reported that two weeks' intensive insulin therapy can achieve better long-term glycaemic control than oral antidiabetic medications in patients with new-onset type 2 diabetes [5], associated with restoration of first-phase insulin secretion [5].
Intensive insulin therapy can be administered either by continuous subcutaneous insulin infusion (CSII) or by multiple daily insulin injections, although glycaemic goals are achieved more rapidly with CSII [6]. CSII also achieves more stable blood glucose concentrations when compared to multiple daily insulin injections, and therefore holds greater potential to maintain the acute insulin response at one year in newly diagnosed type 2 diabetes [7]. Among the antidiabetic medications, dipeptidyl peptidase-4 (DPP-4) inhibitors, sitagliptin, increases endogenous glucogan like peptide-1 (GLP-1), and improves $\beta$-cell function to lower the blood glucose levels without occurrence of hypoglycaemic events [8]. It is widely used in the type 2 diabetic patients, even in those with high cardiovascular risk [9]. However, there were no studies about the effects of insulin therapy and sitagliptin on $\beta$-cell function and glycaemic control in newly diagnosed type 2 diabetes.

Therefore, we aimed to assess the effects of combination of CSII and sitagliptin on glycaemic control, $\beta$-cell function and lipid profiles in patients with newly diagnosed type 2 diabetes. 


\section{Methods}

\section{Subjects}

All patients presenting to our institution between 1 Jan 2012 and 30 July 2014 with newly diagnosed type 2 diabetes according to World Health Organization criteria were included in this retrospective study (43 males/13 females; age (mean \pm SE) $46.5 \pm 1.6$ years, BMI $25.5 \pm 0.5$ $\left.\mathrm{kg} / \mathrm{m}^{2}, \mathrm{HbAlc} 11.80 \pm 0.2 \%\right)$ were diagnosed. None had diabetic ketoacidosis, hyperosmolar status or chronic complications of diabetes. Patients with liver, renal and heart dysfunction, those positive for glutamic acid decarboxylase antibody, and those with a history of gastrointestinal symptoms or gastrointestinal surgery during the preceding three months were excluded. All patients provided written informed consent.

\section{Study protocol}

A total of 56 Chinese patients with type 2 diabetes were hospitalized in the Department of Endocrinology and Metabolism of Shanghai Renji Hospital. The protocol was approved by the Human Research Ethics Committee of the Shanghai Renji Hospital, and was conducted in accordance with the Declaration of Helsinki. Each subject provided written informed consent. All had fasting hyperglycaemia (13.42 \pm 0.38 $\mathrm{mmol} / \mathrm{L}$ ) at admission, and were treated with rapid-acting insulin (Insulin Aspart Injection, Novo Nordisk) delivered by insulin pump (Paradigm 712 pump, Medtronic, Northridge, CA) for two weeks. The daily insulin dose was initially $0.4-0.5$ IU per $\mathrm{kg}$, divided into $40 \%$ basal and $60 \%$ bolus administration with subsequent adjustment of doses to achieve fasting blood glucose of $6 \mathrm{mmol} / \mathrm{L}$ and $2 \mathrm{~h}$ postprandial glucose of $8 \mathrm{mmol} / \mathrm{L}$. During the two weeks of insulin therapy, all meals were prepared by dietitians (total energy intake $20-25 \mathrm{kcal} / \mathrm{kg}, 50-60 \%$ from carbohydrate, $15-20 \%$ from protein, and $20-25 \%$ from fat). Additional food was provided only in the event of hypoglycemia. After two weeks, insulin therapy was discontinued and patients commenced oral sitagliptin (100mg, once daily) which was continued for three months.

At baseline, after two weeks' insulin therapy, and after three months sitagliptin therapy, blood was sampled after overnight fasting for blood glucose, insulin and lipid assays. HbAlc and body weight were also measured at baseline and after 3 months' sitagliptin. Arginine was then administered intravenously (5 $\mathrm{g}$ arginine iv) and blood samples collected at $0,2,4,6$, and 8 min to measure insulin concentrations.

\section{Measurements}

Blood glucose concentrations were measured by the hexokinase method (Roche Diagnostics GmbH, Mannheim, Germany). Plasma insulin was assayed by radioimmunoassay kit (Beijing Atom HighTech Co., Ltd; Beijing; China). HbAlc was measured by High Performance Liquid Chromatography. Lipid profiles were determined using a clinical chemistry analyzer (Roche Original Reagents; Stockholm, Sweden).

\section{Statistical Analysis}

$\beta$ cell function was evaluated using HOMA- $\beta$. HOMA $\beta$ was calculated as $20 \times$ fasting insulin/ (fasting plasma glucose-3.5). The insulin response to arginine was calculated as the incremental area under the curve (iAUC) over 8 minutes, using the trapezoidal rule. Insulin resistance was evaluated by HOMA-IR, calculated as fasting plasma glucosexfasting insulin/22.5. Data are shown as mean \pm SE. Paired $t$ tests were used to compare outcome measures before and after each phase of treatment, using statistical software (SPSS 20.0). Comparison of variables between two groups was performed by using repeated measures ANOVA. $P$ values $<0.05$ were considered significant.

\section{Results}

48 patients completed the study. One discontinued due to persisting hyperglycaemia, during the sitagliptin therapy. 7 patients were lost to follow-up due to moving to another city or overseas. The mean maximum daily doses were $0.63 \mathrm{IU} / \mathrm{kg}( \pm 0.02)$. During the insulin intervention period, all patients reached glycaemic goals in 6.9 days $( \pm$ 0.22). During the intensive insulin intervention, hypoglycemia (defined as a blood glucose level is lower than $3.9 \mathrm{mmol} / \mathrm{L}$ ) occurred in 11 patients. There were no severe hypoglycaemic events, defined as requirement of assistant to relief symptom.

Fasting blood glucose concentrations (Figure 1).

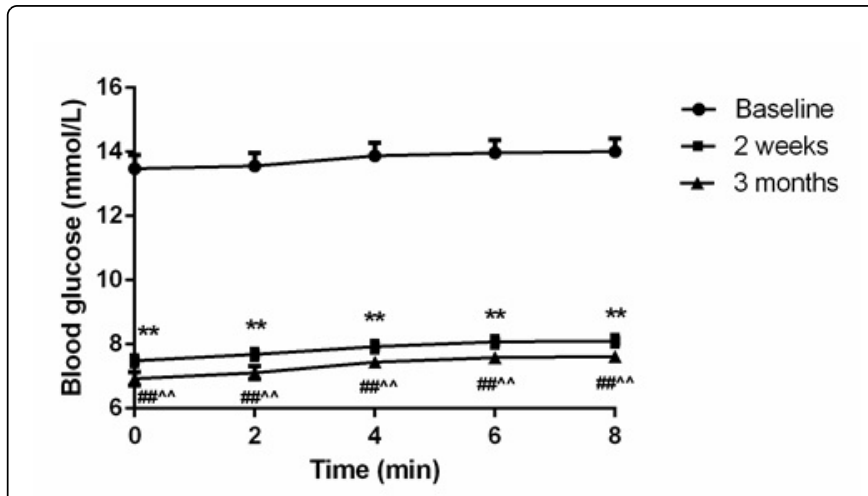

Figure 1: Blood glucose concentrations at baseline, after 2 weeks intensive insulin therapy, and after 3 months sitagliptin, during the arginine stimulation test in patients with type 2 diabetes $(n=48)$. Data are mean $\pm \mathrm{SE}$. ${ }^{* *} \mathrm{P}<0.01$ baseline vs 2 week values; ${ }^{\# \#} \mathrm{P}<0.05$ baseline vs 3 month values; ${ }^{\wedge \wedge} \mathrm{P}<0.012$ week vs 3 month values.

Fasting blood glucose was decreased after insulin therapy compared to baseline values $(7.56 \pm 0.17 \mathrm{mmol} / \mathrm{L}$ vs $13.42 \pm 0.38 \mathrm{mmol} / \mathrm{L}$, $\mathrm{P}<0.01)$. Fasting blood glucose decreased further after 3 months' treatment with sitagliptin $(6.93 \pm 0.21 \mathrm{mmol} / \mathrm{L}, \mathrm{P}<0.01)$.

Plasma insulin concentrations (Figure 2).

There were no differences in fasting plasma insulin concentrations after 2 weeks insulin treatment compared to baseline values (13.3 \pm 0.8 $\mathrm{uIU} / \mathrm{mL}$ vs $18.5 \pm 4.1 \mathrm{uIU} / \mathrm{mL}$ ). However, fasting plasma insulin increased after 3 months treatment with sitagliptin $(16.4 \pm 1.2 \mathrm{uIU} / \mathrm{mL}$, $\mathrm{P}<0.05)$. The insulin response to arginine was reduced after insulin treatment at $\mathrm{t}=4 \mathrm{~min}$ and $6 \mathrm{~min}$, but insulin secretion was significantly increased after 3 month treatment of sitagliptin at $\mathrm{t}=0 \mathrm{~min}, 2 \mathrm{~min}, 4$ min, 6 min and 8 min $(\mathrm{P}<0.05)$. iAUC insulin concentrations did not differ statistically between baseline and after 2 weeks insulin treatment (iAUC $179.19 \pm 16.41 \mathrm{uIU} / \mathrm{mL} . \mathrm{min} v s 150.23 \pm 14.67 \mathrm{uIU} / \mathrm{mL} . \mathrm{min}$ ). 


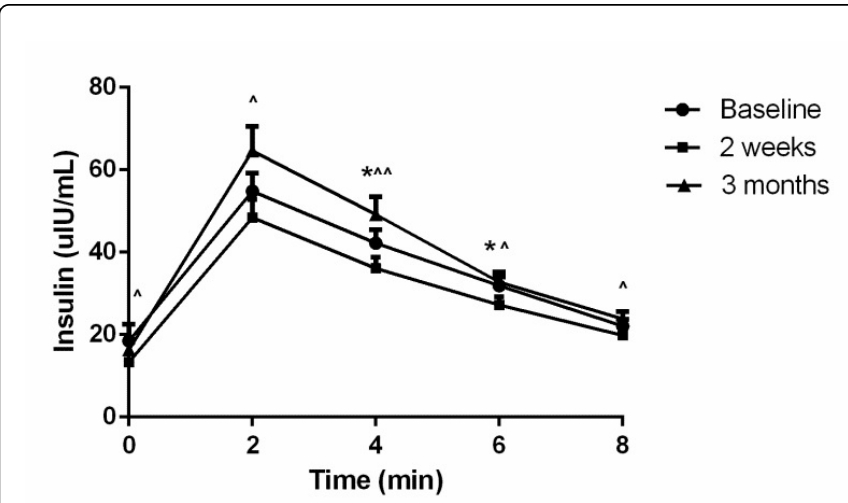

Figure 2: Plasma insulin concentrations at baseline, after 2 weeks intensive insulin therapy, and after 3 months sitagliptin, during the arginine stimulation test in patients with type 2 diabetes $(n=48)$. Data are mean $\pm \mathrm{SE} .{ }^{*} \mathrm{P}<0.05$ and ${ }^{* *} \mathrm{P}<0.01$ baseline vs 2 week values; ${ }^{\#} \mathrm{P}<0.05$ and ${ }^{\# \#} \mathrm{P}<0.01$ baseline vs 3 month values; ${ }^{\wedge} \mathrm{P}<0.05$ and ${ }^{\wedge \wedge} \mathrm{P}<0.012$ week vs 3 month values.

However, iAUC insulin levels increased after 3 months treatment with sitagliptin (iAUC $205.48 \pm 21.32 \mathrm{uIU} / \mathrm{mL}$.min, $\mathrm{P}<0.05$ ). HOMAIR decreased markedly after 2 weeks insulin therapy (4.99 \pm 0.39 vs $12.12 \pm 3.40, \mathrm{P}<0.01)$, but did not change further after 3 months sitagliptin treatment $(4.44 \pm 0.28)$. HOMA- $\beta$ increased after two weeks insulin treatment when compared to baseline (73.0 \pm 5.6 vs $40.2 \pm 7.1$, $\mathrm{P}<0.01)$, and increased further after 3 months oral sitagliptin $(114.76 \pm$ $11.06, \mathrm{P}<0.01)$.

HbA1c (Figure 3).

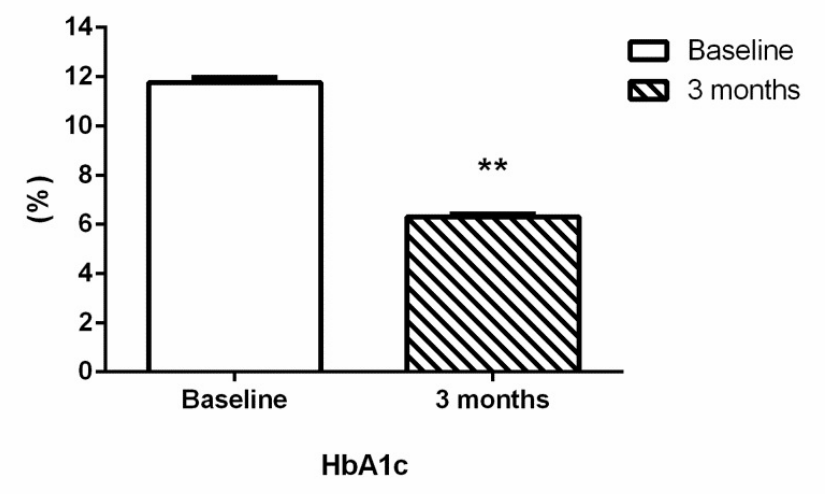

Figure 3: HBAlc at baseline, and after 3 months sitagliptin treatment following initial intensive insulin therapy, in patients with type 2 diabetes $(n=48)$. Data are mean \pm SE. ${ }^{\star} \mathrm{P}<0.05$ and ${ }^{* *} \mathrm{P}<0.01$ baseline vs 3 month values.

HbA1c decreased markedly after 3 months sitagliptin when compared to baseline $(6.3 \pm 0.1 \%, v s 11.8 \pm 0.2 \%, \mathrm{P}<0.01)$.

Serum lipids (Figure 4).

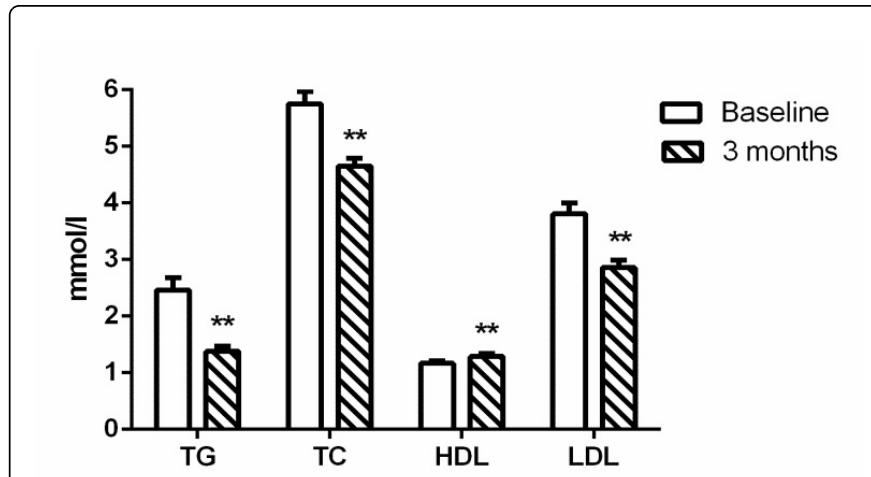

Figure 4: Lipid profile at baseline, and after 3 months sitagliptin treatment following initial intensive insulin therapy, in patients with type 2 diabetes $(\mathrm{n}=48)$. ${ }^{*} \mathrm{P}<0.05$ and ${ }^{* *} \mathrm{P}<0.01$ baseline vs 3 month values.

When compared to baseline, there were reductions after 3 months sitagliptin therapy in TC $(4.7 \pm 0.1 \mathrm{mmol} / \mathrm{L}$ vs $5.8 \pm 0.2 \mathrm{mmol} / \mathrm{L}$, $\mathrm{P}<0.01)$, TG $(1.4 \pm 0.1 \mathrm{mmol} / \mathrm{L}$ vs $2.5 \pm 0.2 \mathrm{mmol} / \mathrm{L}, \mathrm{P}<0.01)$, and $\mathrm{LDL}$ $(2.9 \pm 0.1 \mathrm{mmol} / \mathrm{L}$ vs $3.8 \pm 0.2 \mathrm{mmol} / \mathrm{L}, \mathrm{P}<0.01)$. In contrast, $\mathrm{HDL}$ at the end of treatment increased when compared to baseline $(1.29 \pm 0.05$ $\mathrm{mmol} / \mathrm{L}$ vs $1.17 \pm 0.04 \mathrm{mmol} / \mathrm{L}, \mathrm{P}<0.01)$.

\section{Body weight}

Body weight at the end of treatment did not differ from baseline $(72.3 \pm 0.3 \mathrm{~kg}$ vs $72.1 \pm 0.2 \mathrm{~kg})$.

\section{Discussion}

We have shown, in Chinese patients with newly diagnosed type 2 diabetes and poor glycaemic control, that initial intensive insulin therapy followed by oral sitagliptin not only preserved but even improved beta-cell function over 3 months, with concomitant reductions in fasting blood glucose concentrations, HbA1C, and serum lipids.

Impaired insulin release, particularly for the first phase of secretion, plays a pathogenic role in newly diagnosed patients with type 2 diabetes mellitus. Early intensive insulin treatment can eliminate hyperglycaemic toxicity and thereby improve $\beta$-cell function, with improved glycaemic control over 12 months when compared to less intensive initial therapy with oral agents $[10,11]$. We enrolled newly diagnosed patients with marked fasting hyperglycemia (mean fasting blood glucose $>13 \mathrm{mmol} / \mathrm{L}$ ) and even worse overall glycaemic control than those reported previously (mean $\mathrm{HbAlC}>11 \%$ compared to $<10 \%)$ [11]. Fasting blood glucose predominates over postprandial glycaemia as a determinant of HbA1c at such high levels [12], and even more modest elevation of fasting glycaemia $(>7 \mathrm{mmol} / \mathrm{L})$ can impair first phase insulin secretion [13]. We chose to evaluate beta cell function with the arginine stimulation test in addition to HOMA- $\beta$, given that it is less susceptible to being affected by glucotoxicity when compared to the intravenous glucose test or meal tolerance tests. Similar to the previous study, blood glucose levels were reduced and HOMA- $\beta$ and HOMA-IR were improved after two weeks insulin pump therapy, but the insulin response to arginine was not enhanced. 
Page 4 of 5

The "incretin" hormones, glucose-dependent insulinotropic polypeptide (GIP) and GLP-1, are responsible for $50-70 \%$ of the insulin response to meals in healthy humans [14]. Although the insulinotropic effects of GIP are diminished, those of GLP-1 are relatively preserved in patients with type 2 diabetes. DPPIV inhibitors, such as sitagliptin, increase concentrations of the active form of GLP-1 to lower blood glucose levels in glucose-dependent manner, and tend to reduce $\mathrm{HbAlc}$ by $0.5-1.0 \%$ [15]. It has been reported that the DPPIV inhibitors are more effective in Asian patients than in causcasian due to the differences of insulin sensitivity [16]. In our study, $\mathrm{HbA1C}$ was decreased by $4.5 \%$ after treatment of insulin and sitagliptin. Following the two week CSII, sitagliptin further idealized glycaemic control which was related to further improvement of $\beta$ cell function. Both the acute insulin release and HOMA- $\beta$ was increased after sitagliptin dosage in newly diagnosed type 2 diabetes. The data is different from the previous study which concludes sitagliptin might not be associated with improvement of beta-cell function [17]. However, the population was small in Retnakaran's study. The study design was also different. It included patients with 2-8 years duration of type 2 diabetes and they were on $0-2$ oral diabetic medications.

In addition to glucotoxicity, $\beta$-cell damage and impaired insulin secretion in patients with poor glycaemic control have been linked to lipotoxicity [18]. Consistent with previous studies $[19,20]$, we observed an improvement in the lipid profile with 3 months sitagliptin treatment in our patients. As in previous studies involving DPP IV inhibitors, sitagliptin was not associated with weight loss [21,22], suggesting that DPP-4 inhibitors may improve lipid oxidation rate rather than storage in adipose tissue [23].

There are some limitations in our study. Firstly, our study was observational, without a comparator group during either the intensive insulin phase or the sitagliptin phase. However, the benefits of initial intensive insulin therapy on $\beta$ cell function have already been established in comparison to an active control [11], and we believe that these gains in newly diagnosed type 2 patients are preserved and further enhanced after 3 months treatment with sitagliptin is an important one in our observation. Secondly, we did not measure plasma glucagon concentrations, but the emphasis of our study was on beta cell rather than a cell function. Finally, the duration of our observations was relatively short, and more prolonged observation during sitagliptin treatment, after a similar initial intensive insulin regimen, would be of interest.

In summary, we demonstrated that after 2 weeks of initial intensive insulin therapy, $\beta$ cell function and glycaemic control were improved in patients with newly diagnosed type 2 diabetes. Moreover, $\beta$ cell function was preserved and further enhanced after three months treatment with sitagliptin. The capacity for DPP IV inhibitors to preserve beta cell function over the longer term in patients in this context, when compared to other therapies, should be examined in subsequent clinical trials.

\section{Acknowledgment}

We want to thank the nursing staff at Shanghai Renji Hospital, and especially Yawen Chen, for their assistance with the study. This work was supported by grants from the National Natural Science Foundation of China (NSFC 81670728), Clinical research funding in Renji Hospital affiliated to Shanghai Jiaotong University (PYZY16-020) and Research funding in Renji Hospital, south campus, affiliated to Shanghai Jiaotong University (2016PWZH01).

\section{Disclosure}

All authors declare that there is no conflict of interest that could be perceived as prejudicing the impartiality of the research reported.

\section{References}

1. Xu Y, Wang L, He J, Bi Y, Li M, et al. (2013) Prevalence and control of diabetes in Chinese adults. JAMA 310: 948-959.

2. Wu CZ, Pei D, Hsieh AT, Wang K, Lin JD, et al. (2010) Comparison of insulin sensitivity, glucose sensitivity, and first phase insulin secretion in patients treated with repaglinide or gliclazide. Arch Pharm Res 33: 411-416.

3. Garber AJ, Abrahamson MJ, Barzilay JI, Blonde L, Bloomgarden ZT, et al. (2013) AACE comprehensive diabetes management algorithm 2013. Endocr Pract 19: 327-336.

4. Chen HS, Wu TE, Jap TS, Hsiao LC, Lee SH, et al. (2008) Beneficial effects of insulin on glycemic control and beta-cell function in newly diagnosed type 2 diabetes with severe hyperglycemia after short-term intensive insulin therapy. Diabetes Care 31: 1927-1932.

5. Hu Y, Li L, Xu Y, Yu T, Tong G, et al. (2011) Short-term intensive therapy in newly diagnosed type 2 diabetes partially restores both insulin sensitivity and beta-cell function in subjects with long-term remission. Diabetes Care 34: 1848-1853.

6. Grunberger G, Bailey TS, Cohen AJ, Flood TM, Handelsman Y, et al. (2010) Statement by the American Association of Clinical Endocrinologists Consensus Panel on insulin pump management. Endocr Pract 16: 746-762.

7. Walsh J, Roberts R, Bailey T (2010) Guidelines for insulin dosing in continuous subcutaneous insulin infusion using new formulas from a retrospective study of individuals with optimal glucose levels. J Diabetes Sci Technol 4: 1174-1181.

8. Mu J, Woods J, Zhou YP, Roy RS, Li Z, et al. (2006) Chronic inhibition of dipeptidyl peptidase- 4 with a sitagliptin analog preserves pancreatic betacell mass and function in a rodent model of type 2 diabetes. Diabetes 55: 1695-1704.

9. Green JB, Bethel MA, Armstrong PW, Buse JB, Engel SS, et al. (2015) Effect of Sitagliptin on Cardiovascular Outcomes in Type 2 Diabetes. N Engl J Med 373: 232-242.

10. Ma J, Liu LY, Wu PH, Liao Y, Tao T, et al. (2014) Comparison of metformin and repaglinide monotherapy in the treatment of new onset type 2 diabetes mellitus in China. J Diabetes Res 2014: 294017.

11. Weng J, Li Y, Xu W, Shi L, Zhang Q, et al. (2008) Effect of intensive insulin therapy on beta-cell function and glycaemic control in patients with newly diagnosed type 2 diabetes: a multicentre randomised parallelgroup trial. Lancet 371: 1753-1760.

12. Monnier L, Lapinski H, Colette C (2003) Contributions of fasting and postprandial plasma glucose increments to the overall diurnal hyperglycemia of type 2 diabetic patients: variations with increasing levels of $\mathrm{HbA}(1 \mathrm{c})$. Diabetes Care 26: 881-885.

13. Li YB, Zhu DL, Tian HM, Shi LX, Luo ZJ, et al. (2006) Characteristics of dysfunction of islet beta-cell in newly diagnosed type 2 diabetic patients. Zhonghua Yi Xue Za Zhi 86: 2537-2541.

14. McIntyre N, Holdsworth CD, Turner DS (1964) New Interpretation of Oral Glucose Tolerance. Lancet 2: 20-21.

15. Drucker DJ, Nauck MA (2006) The incretin system: glucagon-like peptide-1 receptor agonists and dipeptidyl peptidase- 4 inhibitors in type 2 diabetes. Lancet 368: 1696-1705.

16. Cai X, Han X, Luo Y, Ji L (2015) Efficacy of dipeptidyl-peptidase-4 inhibitors and impact on beta-cell function in Asian and Caucasian type 2 diabetes mellitus patients: A meta-analysis. J Diabetes 7: 347-359.

17. Retnakaran R, Qi Y, Opsteen C, Vivero E, Zinman B (2010) Initial shortterm intensive insulin therapy as a strategy for evaluating the preservation of beta-cell function with oral antidiabetic medications: a pilot study with sitagliptin. Diabetes Obes Metab 12: 909-915. 
Citation: $\quad$ Xu H, Zhou H, Teng X, Lin T, Feng R, et al. (2018) Effect of Initial Intensive Insulin Therapy Followed by Sitagliptin on $\beta$ Cell Function in Patients with New Onset Type 2 Diabetes. J Diabetes Metab 9: 803. doi:10.4172/2155-6156.1000803

Page 5 of 5

18. Weir GC, Bonner-Weir S (2004) Five stages of evolving beta-cell dysfunction during progression to diabetes. Diabetes 3: S16-S21.

19. Shigematsu E, Yamakawa T, Kadonosono K, Terauchi Y (2014) Effect of sitagliptin on lipid profile in patients with type 2 diabetes mellitus. J Clin Med Res 6: 327-335.

20. Derosa G, Ragonesi PD, Fogari E, Cicero AF, Bianchi L, et al. (2014) Sitagliptin added to previously taken antidiabetic agents on insulin resistance and lipid profile: a 2-year study evaluation. Fundam Clin Pharmacol 28: 221-229.

21. Umezawa S, Kubota A, Maeda H, Kanamori A, Matoba K, et al. (2015) Two-year assessment of the efficacy and safety of sitagliptin in elderly patients with type 2 diabetes: Post hoc analysis of the ASSET-K study. BMC Endocr Disord 15: 34.

22. Plosker GL (2014) Sitagliptin: a review of its use in patients with type 2 diabetes mellitus. Drugs 74: 223-242.

23. Boschmann M, Engeli S, Dobberstein K, Budziarek P, Strauss A, et al. (2009) Dipeptidyl-peptidase-IV inhibition augments postprandial lipid mobilization and oxidation in type 2 diabetic patients. J Clin Endocrinol Metab 94: 846-852. 